\title{
Saberes matemáticos nas escolas normais: Brasil, França e Portugal (séculos XIX e XX)
}

\author{
Mathematical knowledge in normal schools: \\ Brazil, France and Portugal (19th and 20th centuries) \\ Conocimientos matemáticos en escuelas normales: \\ Brasil, Francia y Portugal (siglos XIX y XX)
}

\author{
ANDRÉIA DALCIN ${ }^{1}{ }^{1}$ \\ ELISABETE ZARDO BÚRIGO (1 1 \\ ${ }^{1}$ Universidade Federal do Rio Grande do Sul, Porto Alegre, RS, Brasil.
}

\begin{abstract}
$A^{\text {parir }}$ partir do século XIX, em diferentes países ocidentais e em diferentes regiões do Brasil, as escolas normais são constituídas como instituições dedicadas à formação de professores para as escolas elementares. Enquanto espaços de formação, contribuíram ao longo do tempo para a construção de práticas pedagógicas e sociais que forjaram diferentes elementos da cultura escolar, em especial, da escola primária. Neste sentido, participaram da configuração dinâmica de uma cultura escolar própria da escola primária, por meio da formação de professores e dos chamados especialistas, da produção de materiais e da divulgação de ideias pedagógicas.
\end{abstract}

As escolas normais começaram a aparecer no cenário brasileiro a partir da terceira década do século XIX. Em 1835, foi criada a primeira Escola Normal em Niterói, no Rio de Janeiro; em 1836 foi criada a Escola Normal na Bahia, e a elas se seguiram várias outras. Sendo que "o modelo que se implantou foi o europeu, mais especificamente o francês, resultante de nossa tradição colonial e do fato de que o projeto nacional era emprestado às elites, de formação cultural europeia", sem, no entanto, desconsiderar "sua articulação com o contexto nacional e com as contradições internas de nossa sociedade" (TANURY, 2000, p. 15).

Inicialmente, as escolas normais integraram um processo de descentralização do governo imperial, e constituição da autonomia das províncias, para organizar seus sistemas de ensino, o que levou a uma diversidade "no incremento da instrução elementar e secundária, porque somente as províncias com recursos financeiros e projetos voltados para a implantação da instrução primária e secundária dariam um passo à frente na efetivação desses graus de ensino" (MARTINS, 2009, p. 176-177). Além disso, segundo Saviani (2008, p. 7), em um processo intermitente, as escolas normais eram criadas, em seguida fechadas e, depois, reabertas, devido a diferentes fatores estudados pela historiografia.

Com o passar do tempo, ao longo dos primeiros anos da República, as escolas normais vão cada vez mais constituindo-se como um lugar privilegiado para a formação de professores de modo a assumir a instrução da "nova sociedade" por meio de métodos "ativos", "concretos" e "racionais" (DAROS; DANIEL, 2008). Os "saberes a ensinar" constituem-se, pouco a pouco, como elementos constitutivos dessa formação e da especialização dos professores dos primeiros anos escolares (VALENTE, 2017). Ou seja, as escolas normais tornam-se espaços de divulgação e de experimentação de ideais, materiais e práticas pedagógicas que se materializam nos modos de ensinar os saberes escolares. Nesse cenário, os saberes matemáticos - inicialmente componentes da tríade "ler, escrever e contar" - são reconfigurados, em um contexto de expansão do ensino elementar, de atribuição de novas finalidades à escola e sob a inspiração de movimentos pedagógicos de variadas vertentes.

Os artigos que compõem o presente dossiê dedicam-se, segundo diferentes perspectivas e enfocando momentos distintos, ao estudo dos modos como as escolas normais reconfiguram os saberes matemáticos, ao longo dos séculos XIX e XX.

O artigo que abre este dossiê, intitulado "Ensino de matemática nas escolas normais primárias francesas, 1830-1848: desafios sociais e culturais para a formação de professores primários", de autoria de Renaud d'Enfert, 
trata da constituição das escolas normais primárias na França, a partir dos anos 1830, destinadas à formação de professores primários. As escolas normais enfrentam tensões decorrentes da dualidade escolar - a escola primária é a escola do povo, e o ensino secundário é destinado às classes privilegiadas. As diretrizes oficiais prescrevem uma formação orientada para os saberes práticos, que deveriam predominar na escola primária, mas a cultura da escola secundária, que prioriza o estudo das teorias e o pensamento dedutivo, também se faz presente pela ação docente dos formadores.

Ainda no cenário europeu, o artigo "A formação profissional em escolas primárias e em escolas normais primárias portuguesas (1844-1926)", de autoria de José Manuel Matos, Alexandra Rodrigues e Rui Candeias, traz um estudo abrangente sobre as legislações que introduziram uma dimensão profissionalizante no ensino primário português, entre 1844 e 1930, sobre os saberes matemáticos presentes nessas reformas, e sobre a formação de professores para o ensino desses saberes. Desde 1844 o ensino primário português passou a prever, após um $1^{\mathrm{O}}$ grau de formação genérica centrada na trilogia "ler, escrever e contar", um $2^{\circ}$ grau, designado por complementar, e entre 1911 e 1930 um terceiro grau, designado por superior, com cursos práticos especiais para o ensino agrícola, industrial, comercial ou marítimo, de acordo com a localização das escolas. Nesse contexto, os autores analisam os programas das escolas normais primárias, segundo a legislação estabelecida entre 1860 e 1926, procurando especificamente indícios de intenções curriculares profissionalizantes.

Direcionando o olhar para o Brasil, temos dois blocos, cada qual composto por quatro artigos. O primeiro bloco é composto por textos que analisam diferentes cursos normais ou de especialização para professores primários em instituições brasileiras, em um período específico.

Abre o primeiro bloco, o artigo "Formação de professores e programas de ensino de Matemática nos Institutos Normais de Educação: uma análise da Escola Primária da Bahia (1836-1960)", de autoria de Rosemeire dos Santos Amaral, Irani Parolin Santana e Claudinei de Camargo Sant'Ana, que traz uma análise histórica dos Cursos de Formação de Professores e dos Programas de Ensino de Matemática para a Escola Primária na Bahia entre 1836 (ano da instituição da primeira escola normal do estado) e 1960 (década demarcada pelo Movimento da Matemática Moderna), levando-se em conta as reformas educacionais estaduais de 1890, 1913, 1918 e 1925 e as determinações para a estrutura e o funcionamento do ensino primário e dos institutos normais de educação.

Já o artigo "Formação de professores nas escolas Wenceslau Braz e Técnica Nacional: o ensino de Matemática", de autoria de Elmha Coelho e Arlete de
Jesus Brito, discute os cursos de formação de professores realizados pela Escola Normal de Artes e Ofícios e pela Escola Técnica Nacional no Rio de Janeiro. A Escola Normal de Artes e Ofícios Wenceslau Braz foi criada pelo Decreto 1800 de 1917, e iniciou os seus cursos, efetivamente, em agosto de 1919, tendo por finalidade formar professores, mestres e contramestres para os vários institutos e escolas profissionais, e tendo, ainda, como objetivo o preparo professores de trabalhos manuais para escolas primárias municipais. Foi reinaugurada, em novo prédio em 1944, como Escola Técnica Nacional. As autoras, no diálogo com a legislação da época e os documentos da escola, analisam a trajetória dessas instituições, que eram consideras as "únicas" escolas que formavam professores para o ensino industrial, e enfatizam os programas e a matemática ensinada.

$\mathrm{O}$ artigo "Inserção da Matemática Moderna na formação de normalistas do Instituto de Educação Assis Brasil", de autoria de Circe Mary Silva da Silva e Makele Verônica Heidt, analisa a inserção do Movimento da Matemática Moderna na formação de normalistas no Instituto de Educação Assis Brasil (IEAB), em Pelotas, no período de 1964-1970, por meio da participação da professora Cecy da Nova Cruz Sacco, que atuou na instituição de 1938 a 1970. A professora destaca-se por seu protagonismo, como uma agente que se apropriou das ideias do movimento e as colocou em prática no curso de formação de professores primários entre os anos de 1960-1970.

O processo de formação de professores primários amplia-se para os cursos de especialização realizados após o Curso Normal. Neste sentido, o artigo "O Curso de Especialização em Didática da Matemática Moderna na Escola Primária no Instituto de Educação de Porto Alegre", de autoria de Sara Regina da Silva e Andréia Dalcin, divulga um estudo realizado sobre o Curso de Especialização em Didática da Matemática Moderna na Escola Primária, ofertado entre 1966 e 1972, no Instituto de Educação General Flores da Cunha, em Porto Alegre. O referido curso, destinado a professores primários, préprimários e que ministravam Didática da Matemática em cursos normais, contribuiu para o processo de circulação no Rio Grande do Sul das ideias, conteúdos e metodologias que caracterizavam o Movimento da Matemática Moderna.

O segundo bloco de artigos, toma como objeto de estudo diferentes fontes históricas, que possibilitam um olhar para o interior dos cursos e das escolas normais: suas práticas e perspectivas teórico-metodológicas no âmbito da formação de professores no que tange ao ensino de matemática.

O artigo "A matemática nas avaliações das normalistas da Escola Normal Caetano de Campos (década de 1940)", de Maria Célia Leme da Silva e Adauto Douglas 
Parré, analisa as avaliações, designadas como "plano globalizado", que foram produzidas na disciplina de Metodologia e Prática do Ensino Primário, no último ano da formação docente na referida instituição, e apresenta Cálculo e Geometria como assuntos a serem abordados. As autoras examinaram um conjunto de avaliações realizadas por normalistas na década de 1940, de modo a identificar como a matemática esteve presente e participou da formação de professores em tempos de Escola Nova.

Um registro no caderno escolar de uma aluna que frequentou o segundo ano do curso primário do Instituto de Educação General Flores da Cunha, na cidade de Porto Alegre, no ano de 1968, é disparador de estudo apresentado no artigo "Saias e blusas: invenções para aprender a multiplicar com a Matemática Moderna", de autoria de Elisabete Zardo Búrigo, Nicolas Giovani da Rosa e Mayara Becker Oliveira da Silva. Pelo cruzamento do registro com outras fontes localizadas no acervo do Laboratório de Matemática do referido Instituto, buscou-se identificar conexões entre as aulas de matemática daquela turma do segundo ano primário e as movimentações de renovação do ensino de matemática em curso, naquela época, no Rio Grande do Sul, na cidade de Porto Alegre e, mais precisamente, no Curso de Especialização em Didática da Matemática Moderna para professores primários, que é objeto do artigo de Sara Regina da Silva e Andréia Dalcin.

$\mathrm{O}$ artigo "Referências para ensinar Matemática Moderna no primário: o material Cuisenaire e a sistematização de saberes", de autoria de Maria Cristina Araújo de Oliveira, apresenta um estudo sobre os saberes para ensinar matemática no ensino primário sistematizados em manuais pedagógicos, que circularam em diferentes estados do Brasil entre as décadas de 1960 e 1970, tomando como foco o ensino de números e operações pelo método Cuisenaire. Na década de 1970, diferentes grupos de estudos do ensino de matemática desenvolveram cursos de formação com o intuito de capacitar - termo usado à época - os professores primários para ensinarem a Matemática Moderna. Dentre os materiais que se associavam às propostas, destacadamente estava o material de Cuisenaire. $\mathrm{O}$ artigo problematiza o método de Cuisenaire, buscando rastros de sua circulação no Brasil, na perspectiva de discutir o processo de disseminação e institucionalização de saberes para ensinar matemática.

Encerrando o dossiê, temos "Memórias de uma normalista: entrevista com Beatriz Daudt Fischer". A entrevista, de autoria de Diogo Franco Rios e Maria Cecília Bueno Fischer, enfocou as memórias do período em que Beatriz estudou na Escola Normal Santa Catarina, em Novo Hamburgo, Rio Grande do Sul, de 1964 a 1967, mais especificamente, sobre a matemática presente no Curso e no estágio realizado em uma turma de primeiro ano primário no Ginásio São Luiz, na mesma cidade.

Desejamos, com esses artigos, contribuir com os estudos nos campos da História da Educação Matemática e da Formação de Professores, divulgando pesquisas realizadas, potencializando discussões e ampliando os modos de ver e pensar sobre os processos de circulação e apropriação dos saberes matemáticos nas instituições formadoras do passado e do presente.

\section{REFERÊNCIAS}

DAROS, M. D.; DANIEL, L. S. O Curso Normal em Santa Catarina: o processo de construção de um projeto de formação de professores coadunado os ideais de nacionalização e "cientifização" do ensino. In: FREITAS, A. G. B.; LOPES, A.P.C.; ARAÚJO, J. C. S. (org.). As Escolas Normais no Brasil: do império à república. Campinas: Alínea, 2008. p. 249-262. https://doi.org/10.11606/t.7.2008.tde-16042008143619

MARTINS, A. M. S. Breves reflexões sobre as primeiras Escolas Normais no contexto educacional brasileiro, no século XIX. Revista HISTEDBR On-line, Campinas, n. 35, p. 173-182, set. 2009. https://doi.org/10.20396/rho.v9i35. 8639621

SAVIANI, D. Prefácio. In: FREITAS, A. G. B.; LOPES, A. P. C.; ARAÚJO, J. C. S. (org.). As Escolas Normais no Brasil: do império a república. Campinas: Alínea, 2008.

TANURY, L. M. História da formação de professores. Revista Brasileira de Educação, Rio de Janeiro, n. 1, p. 61-89, maio/ago. 2000.

VALENTE, W. R. A matemática a ensinar e a matemática para ensinar: os saberes para a formação do educador matemático. In: HOFSTETTER, R.; VALENTE, W. R. (org.). Saberes em (trans)formação: tema central da formação de professores. São Paulo: Livraria da Física, 2017. p. 201-228. https://doi. org/10.14393/che-v17n1-2018-17

Recebido em: 11/6/2019.

Aprovado em: 18/6/2019

Publicado em: 8/11/2019.

Endereço para correspondência:

Andréia Dalcin

Av. Paulo Gama, 110 - Farroupilha

90046-900, Porto Alegre, RS, Brasil

\section{Autoras:}

ANDRÉIA DALCIN

Doutora em Educação, área de Educação Matemática pela Universidade Estadual de Campinas (UNICAMP). Docente na Universidade Federal do Rio Grande do Sul (UFRGS), Porto Alegre, RS, Brasil.

Orcid: https://orcid.org/0000-0003-2488-8801

E-mail: andreia.dalcin@ufrgs.br

Elisabete Zardo Búrigo

Doutora em Educação pela Universidade de São Paulo (USP), licenciada em Matemática. Docente na Universidade Federal do Rio Grande do Sul (UFRGS), Porto Alegre, RS, Brasil.

Orcid: http://orcid.org/0000-0003-1532-7586

E-mail: elisabete.ufros@br

Endereço: Av. Bento Gonçalves, 9500, Prédio 43-111 - Agronomia

91509-900, Porto Alegre, RS, Brasil 